\title{
Effects of university affiliation and "school spirit" on color preferences: Berkeley versus Stanford
}

\author{
Karen B. Schloss • Rosa M. Poggesi • Stephen E. Palmer
}

Published online: 5 March 2011

(C) The Author(s) 2011. This article is published with open access at Springerlink.com

\begin{abstract}
The ecological valence theory (EVT) posits that preference for a color is determined by people's average affective response to everything associated with it (Palmer \& Schloss, Proceedings of the National Academy of Sciences, 107, 8877-8882, 2010). The EVT thus implies the existence of sociocultural effects: Color preference should increase with positive feelings (or decrease with negative feelings) toward an institution strongly associated with a color. We tested this prediction by measuring undergraduates' color preferences at two rival universities, Berkeley and Stanford, to determine whether students liked their university's colors better than their rivals did. Students not only preferred their own colors more than their rivals did, but the degree of their preference increased with self-rated positive affect ("school spirit") for their university. These results support the EVT's claim that color preference is caused by learned affective responses to associated objects and institutions, because it is unlikely that students choose their university or develop their degree of school spirit on the basis of preexisting color preferences.
\end{abstract}

Keywords Human visual perception - Color aesthetics . Ecological valence theory $($ EVT) - Individual differences . Color preference

Most people have relatively strong and idiosyncratic color preferences, but little is known about why they have the preferences they do (Eysenck, 1941; Granger, 1955; Guilford \& Smith, 1959; McManus, Jones, \& Cottrell, 1981; Hurlbert \& Ling, 2007). Palmer and Schloss (2010) recently formulated and tested the ecological valence theory (EVT), stating that people's average color preferences are determined by their average preferences for all objects and

K. B. Schloss $(\bowtie) \cdot$ R. M. Poggesi $\cdot$ S. E. Palmer Psychology Department, University of California, Berkeley, CA 94720-1650, USA

e-mail: kschloss@berkeley.edu institutions associated with those particular colors. In brief, the EVT posits that people like colors to the extent that they are associated with things that those people like (e.g., blues and cyans, associated with positively valued clear sky and clean water) and dislike colors to the extent that they are associated with things that those people do not like (e.g., browns and olive colors, associated with negatively valued feces and rotting food). Palmer and Schloss found that people's average preference for a given color could be predicted from its weighted affective valence estimate (WAVE): the average of the liking/disliking ratings of all things associated with that color, weighted by the similarity of the given color to the color of each associate. Most colors have both positive and negative associates, but the weighted average over all associates for each color explained $80 \%$ of the variance (with no estimated parameters) in average preference ratings of 32 colors.

The EVT further implies that individual differences in color preferences can be explained by learning from idiosyncratic color-related experiences. Such differences should be detectable by identifying groups of people affiliated with an institution that is strongly associated with particular colors and determining whether those people's preferences for the associated colors are correlated with the strength of their positive/negative emotional response to that institution.

Many cultural institutions have strong color associations in modern society: nations through flags, sports teams through uniforms, corporate brands through logos, and American universities through school colors. Members of a given university community, for example, tend to wear clothes, drink from mugs, write in notebooks, and see signs in their school's colors. At sporting events, students often dress in school colors - and sometimes even paint their bodies in them-to broadcast their fervent allegiance. With so many emotionally charged experiences so closely linked to particular colors and color combinations, do students at universities actually come to like their school's colors more than others do? Moreover, do their preferences for those 
colors correlate with the strength of their positive (or negative) affect toward the institution-their level of "school spirit" - as the EVT implies? ${ }^{1}$ In this article, we test these predictions using not only the positive affect students typically feel toward their own university, but the negative affect they often feel for a rival school.

Among American universities, strong rivalries often arise when athletic competition is involved, but scholastic rivalries are often present as well. The well-known rivalry between the University of California, Berkeley, and Stanford University is a classic example involving both components. In this rivalry, many students develop not only a strong positive investment in their own school, but also a negative investment in the rival institution. Although preference for one's institution's colors and dislike for its rival's colors may seem inconsequential, it may be socially quite adaptive to share such color preferences with one's community. At Berkeley, for example, it is socially acceptable - and even desirable among some student groups - to shout, "Take off that red shirt!" when they see another Berkeley student wearing a Stanford red shirt on campus, especially right before the "Big Game" clash between their two football teams. One Berkeley professor even reports that his teaching ratings improved after he stopped lecturing in a red sweater! Could such negativity actually cause students to dislike the rival's colors to a degree that depends on their school spirit, as the EVT implies?

We tested these predictions by measuring Berkeley and Stanford undergraduates' preferences for the single colors (Experiment 1) and color pairs (Experiment 2) associated with both universities. We also measured each student's level of "school spirit" for his/her respective university through a self-report questionnaire to test the EVT's prediction that differences between color preferences among students at the two schools will be present to the degree that students have positive emotional associations with their own university and negative emotional associations toward the rival university.

\section{Experiment 1}

Preference for single colors

Experiment 1 measured students' preferences for four colors specifically matched to the characteristic colors

\footnotetext{
${ }^{1}$ The likelihood of finding reliable school spirit correlations will depend on other factors as well. One is how unique the colors are to the institution. If they are purple and white, spirit-preference correlations should be greater for purple than for white, because purple has many fewer associations than white. Another factor is baseline color preference. A well-liked color (e.g., blue) will be less likely to show increases due to positive school spirit, due to ceiling effects, and strongly disliked colors (e.g., olive) will be less likely to show decreases due to negative school spirit, due to floor effects.
}

found on apparel sold at the university store: Berkeley blue (Berkeley's primary color, a very dark, slightly purplish "navy" blue), Berkeley gold (Berkeley's secondary color, a nonmetallic, highly saturated orangish yellow), Stanford red (Stanford's primary color, a dark, highly saturated, slightly orangish "cardinal" red), and Stanford white (Stanford's secondary color, a prototypical white). These four colors were randomly intermixed with the 32 chromatic colors studied by Palmer and Schloss (2010) and four other, achromatic, colors so that participants would be unlikely to realize that the experiment concerned Berkeley and Stanford colors, since they comprised only $10 \%$ of the trials (if white is included; $7.5 \%$ if white is not included). Participants' responses were therefore unlikely to reflect "demand characteristics." The participants later rated their amount of school spirit for their own university, which was then correlated with color preferences.

\section{Method}

Participants Fifty-seven Berkeley participants (75\% female) were tested at Berkeley and 46 Stanford participants ( $72 \%$ female) were tested at Stanford. No participants were color deficient when screened with the Dvorine Pseudo-Isochromatic Plates. All gave informed consent, and the Committee for the Protection of Human Subjects at the University of California, Berkeley, approved the experimental protocol.

Design The 40 colors tested in this experiment (see Table 1) included the 32 chromatic colors from the Berkeley Color Project (BCP; see Palmer \& Schloss, 2010), the four university-specific colors (Berkeley blue, Berkeley gold, Stanford red, and Stanford white), and four achromatic colors (black and three intermediate grays). Table 1 shows the Munsell coordinates and the corresponding CIE 1931 xyY coordinates obtained from the Munsell renotation table (Wyszecki \& Stiles, 1967). The three chromatic universityspecific colors were determined by perceptual matches in daylight between standard, unused Berkeley and Stanford apparel and Munsell chips (glossy series) and were converted to CIE xyY coordinates using the same Munsell renotation table. The chromaticity for all achromatic colors (including Stanford white) was CIE Illuminant C ( $x=.310$, $y=.316$ ), which appeared achromatic against the background color, which had essentially the same chromaticity.

Displays Each display consisted of a $100 \times 100$ pixel square centered on the computer monitor above a 400-pixel response scale. Stanford students completed the experiment on a 19-in. Dell E196FPf monitor (1,024 $\times 768$ resolution), and Berkeley students on either the same Dell monitor or a 20 -in. iMac computer $(1,280 \times 768$ resolution), both calibrated using a 
Table 1 CIE 1931 values and Munsell values for the 32 chromatic colors (from Palmer \& Schloss, 2010) and CIE 1931 values for the four achromatic colors (CIE Illuminant $\mathrm{C}$ ) and the four university-specific colors

\begin{tabular}{|c|c|c|c|c|c|c|}
\hline Color & & $x$ & $y$ & $\mathrm{Y}$ & Hue & Value/Chroma \\
\hline \multirow[t]{4}{*}{ Red } & Saturated & .549 & .313 & 22.93 & $5 \mathrm{R}$ & $5 / 15$ \\
\hline & Light & .407 & .326 & 49.95 & $5 \mathrm{R}$ & $7 / 8$ \\
\hline & Muted & .441 & .324 & 22.93 & $5 \mathrm{R}$ & $5 / 8$ \\
\hline & Dark & .506 & .311 & 7.60 & $5 \mathrm{R}$ & $3 / 8$ \\
\hline \multirow[t]{4}{*}{ Orange } & Saturated & .513 & .412 & 49.95 & $5 \mathrm{YR}$ & $7 / 13$ \\
\hline & Light & .399 & .366 & 68.56 & $5 \mathrm{YR}$ & $8 / 6$ \\
\hline & Muted & .423 & .375 & 34.86 & $5 \mathrm{YR}$ & $6 / 6$ \\
\hline & Dark & .481 & .388 & 10.76 & $5 \mathrm{YR}$ & $3.5 / 6$ \\
\hline \multirow[t]{4}{*}{ Yellow } & Saturated & .446 & .472 & 91.25 & $5 \mathrm{Y}$ & $9 / 12$ \\
\hline & Light & .391 & .413 & 91.25 & $5 \mathrm{Y}$ & $9 / 6.5$ \\
\hline & Muted & .407 & .426 & 49.95 & $5 \mathrm{Y}$ & $7 / 6.5$ \\
\hline & Dark & .437 & .450 & 18.43 & $5 \mathrm{Y}$ & $5 / 6.5$ \\
\hline \multirow[t]{4}{*}{ Chartreuse } & Saturated & .387 & .504 & 68.56 & $5 \mathrm{GY}$ & $8 / 11$ \\
\hline & Light & .357 & .420 & 79.90 & $5 \mathrm{GY}$ & $8.5 / 6$ \\
\hline & Muted & .360 & .436 & 42.40 & $5 \mathrm{GY}$ & $6.5 / 6$ \\
\hline & Dark & .369 & .473 & 18.43 & $5 \mathrm{GY}$ & $4.5 / 6$ \\
\hline \multirow[t]{4}{*}{ Green } & Saturated & .254 & .449 & 42.40 & $3.75 \mathrm{G}$ & $6.5 / 11.5$ \\
\hline & Light & .288 & .381 & 63.90 & $3.75 \mathrm{G}$ & $7.75 / 6.25$ \\
\hline & Muted & .281 & .392 & 34.86 & $3.75 \mathrm{G}$ & $6 / 6.25$ \\
\hline & Dark & .261 & .419 & 12.34 & $3.75 \mathrm{G}$ & $3.75 / 6.25$ \\
\hline \multirow[t]{4}{*}{ Cyan } & Saturated & .226 & .335 & 49.95 & $5 \mathrm{BG}$ & $7 / 9$ \\
\hline & Light & .267 & .330 & 68.56 & $5 \mathrm{BG}$ & $8 / 5$ \\
\hline & Muted & .254 & .328 & 34.86 & $5 \mathrm{BG}$ & $6 / 5$ \\
\hline & Dark & .233 & .324 & 13.92 & $5 \mathrm{BG}$ & $4 / 5$ \\
\hline \multirow[t]{4}{*}{ Blue } & Saturated & .200 & .230 & 34.86 & $10 \mathrm{~B}$ & $6 / 10$ \\
\hline & Light & .255 & .278 & 59.25 & $10 \mathrm{~B}$ & $7.5 / 5.5$ \\
\hline & Muted & .241 & .265 & 28.90 & $10 \mathrm{~B}$ & $5.5 / 5.5$ \\
\hline & Dark & .212 & .236 & 10.76 & $10 \mathrm{~B}$ & $3.5 / 5.5$ \\
\hline \multirow[t]{4}{*}{ Purple } & Saturated & .272 & .156 & 18.43 & $5 \mathrm{P}$ & $4.5 / 17$ \\
\hline & Light & .290 & .242 & 49.95 & $5 \mathrm{P}$ & $7 / 9$ \\
\hline & Muted & .287 & .222 & 22.93 & $5 \mathrm{P}$ & $5 / 9$ \\
\hline & Dark & .280 & .181 & 7.60 & $5 \mathrm{P}$ & $3 / 9$ \\
\hline \multirow[t]{4}{*}{ Achromatic } & Black & .310 & .316 & 0.30 & & \\
\hline & Dark gray & .310 & .316 & 12.34 & & \\
\hline & Med gray & .310 & .316 & 31.88 & & \\
\hline & Light gray & .310 & .316 & 63.90 & & \\
\hline \multirow[t]{2}{*}{ Berkeley } & Blue & .183 & .186 & 1.10 & $2.5 \mathrm{~PB}$ & $2 / 6$ \\
\hline & Gold & .475 & .441 & 69.56 & $10 \mathrm{YR}$ & $8 / 12$ \\
\hline \multirow[t]{2}{*}{ Stanford } & Red & .573 & .324 & 4.60 & $7.5 \mathrm{R}$ & $3 / 10$ \\
\hline & White & .310 & .316 & 116.00 & & \\
\hline
\end{tabular}

Minolta CS100 chroma meter. The software Presentation (www.neurobs.com) was used to generate and display test items during the experiment.

Procedure The colors were presented one at a time in a random order. Participants were instructed to rate how much they liked each color, on a scale from not at all to very much. Ratings were made by moving the cursor along the response scale with the computer mouse and clicking at the appropriate position. Ratings were rescaled to range from 100 to +100 , with the vertical bisecting line for the neutral preference point at 0 . Colors remained on the screen until a response was made, and the next trial began $500 \mathrm{~ms}$ later. Later in the session, participants rated their level of spirit for their own university on a $1-9$ scale $(1=$ anti-spirit to $9=$ tons of spirit, with 5 indicated as a neutral point of no spirit) 
and their level of investment in the Berkeley-Stanford rivalry on a $1-9$ scale $(1=$ not at all, $9=$ intensely, with $5=$ moderately). They also reported which side of the rivalry they were on.

\section{Results and discussion}

We compared Berkeley and Stanford students' overall preferences for the university colors by computing a composite Berkeley-Stanford difference score for each participant: the mean preference rating for Berkeley blue and Berkeley gold minus that for Stanford red and Stanford white. Students at the two universities differed on this combined measure $\left[F(1,101)=8.21, p<.01, \eta^{2}=.08\right],{ }^{2}$ in that Berkeley students liked Berkeley's colors more than Stanford's $(+16.1)$, and Stanford students liked Stanford's colors more than Berkeley's (-9.6). The EVT further predicts that differences in color preferences should covary with students' levels of school spirit. Indeed, the Berkeley-Stanford composite score was positively correlated with school spirit for Berkeley students $(r=+.26, p<.05)$ and negatively correlated with school spirit for Stanford students $(r=-.29, p<.05)$.

Figure 1a compares Berkeley and Stanford students' preference ratings separately for the individual school colors. All four differences were in the predicted direction ( $p=.06$ by a sign test), although not all were individually reliable. Stanford students liked Stanford red more than Berkeley students did $\left[F(1,101)=8.92, p<.01, \eta^{2}=.08\right]$, and there was a marginally significant trend for Berkeley students to like Berkeley gold more than Stanford students $\operatorname{did}\left[F(1,101)=2.30, p=.07, \eta^{2}=.02\right]$. No reliable differences in preference were evident for Berkeley blue $\left[F(1,101)=0.07, p=.40, \eta^{2}=.001\right]$ or Stanford white $\left[F(1,101)=0.07, p=.39, \eta^{2}=.001\right]$.

These comparisons show that the difference between Berkeley and Stanford students' composite preference scores was driven primarily by preference differences in Stanford red and Berkeley gold. The lack of an effect for white may be attributed to the fact that it is well represented in both Berkeley and Stanford's football uniforms, as well as in many other institutional and object contexts, making it far less unique to the Berkeley-Stanford rivalry than the other colors. It is less clear why there is no difference in preference for Berkeley blue. One plausible explanation is that the BerkeleyStanford rivalry may be asymmetrical. If Berkeley and Stanford students are equally positive about their own school but Berkeley students are more strongly anti-Stanford than Stanford students are anti-Berkeley, then the EVT would

\footnotetext{
${ }^{2}$ Unless otherwise specified, all statistical tests were one-tailed, because the EVT makes clear predictions about the direction of the effects.
}

predict that the difference in preferences between the two student groups would be greater for Stanford red than for Berkeley blue. Indeed, Berkeley and Stanford students rated their levels of school spirit for their own university about equally (6.95 and 6.85, respectively; $t<1$ ), but Berkeley students rated themselves as significantly more invested in the rivalry than did Stanford students ${ }^{3}[4.95$ and 4.07, respectively; $t(100)=1.82, p<.05, \eta^{2}=.03$ ].

We also correlated Berkeley and Stanford students' school spirit ratings with their preference for each of the four university colors (see Fig. 1b). Although not all of the correlations between spirit and individual color preference were statistically significant, seven out of the eight were in the predicted direction, which is significant in a sign test $(p=.04)$. Among Berkeley students, the correlations between school spirit and preference for Berkeley blue and Berkeley gold were both positive, although only the latter was reliable $(r=+.10$, $p=.23$, and $r=+.27, p<.05$, respectively), whereas the correlation between Berkeley spirit and preference for Stanford red was reliably negative $(r=-.31, p<.01)$. Surprisingly, preference for Stanford white actually increased with Berkeley spirit $(r=+.30, p=.04$, two-tailed), perhaps because Berkeley athletes often play in mainly white uniforms. This single reversal of the EVT predictions, therefore, has a plausible post-hoc explanation. Among Stanford students, the correlations between school spirit and preference for Stanford red and Stanford white were both positive, although only the latter was reliable $(r=+.10, p=.25$, and $r=+.32, p<.05$, respectively), whereas the correlations between Stanford spirit and preference for Berkeley blue and Berkeley gold were both negative, although not reliably so ( $r=-.06, p=.34$, and $r=-.16, p=.15$, respectively). The low negative correlations may be due to Stanford students' lower investment in the Berkeley-Stanford rivalry (see above).

We tested how preferences for school colors generalize to similar colors by comparing them to Berkeley and Stanford students' preferences for the $\mathrm{BCP}$ colors that were most similar to the university colors. In general, the correlations were less extreme for these $\mathrm{BCP}$ colors than for the corresponding university colors, but in the same direction: BCP dark red (Berkeley students, $r=-.28$; Stanford students, $r=+.10$ ) versus Stanford red (Berkeley students, $r=-.31$; Stanford students, $r=+.24$ ), and BCP saturated yellow (Berkeley students, $r=+.12$; Stanford students, $r=-.11$ ) versus Berkeley gold (Berkeley students, $r=+.27$; Stanford students, $r=-.06)$. These results suggest that the preference effects due to school spirit generalize to similar colors that would likely be given the same linguistic description (e.g., "dark red" or "vivid yellow"), but that this is not a strong effect.

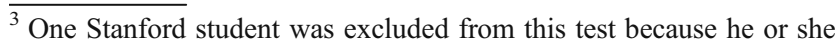
reported being on the Berkeley side of the rivalry. All other students were on their own university's side or on neither side of the rivalry.
} 
Fig. 1 a Berkeley (black bars) and Stanford (white bars) students' preference ratings for Berkeley blue, Berkeley gold, Stanford red, and Stanford white. Error bars represent standard errors of the means. $\mathbf{b}$ Berkeley and Stanford students' correlations between spirit scores and preference for Berkeley blue, Berkeley gold, Stanford red, and Stanford white

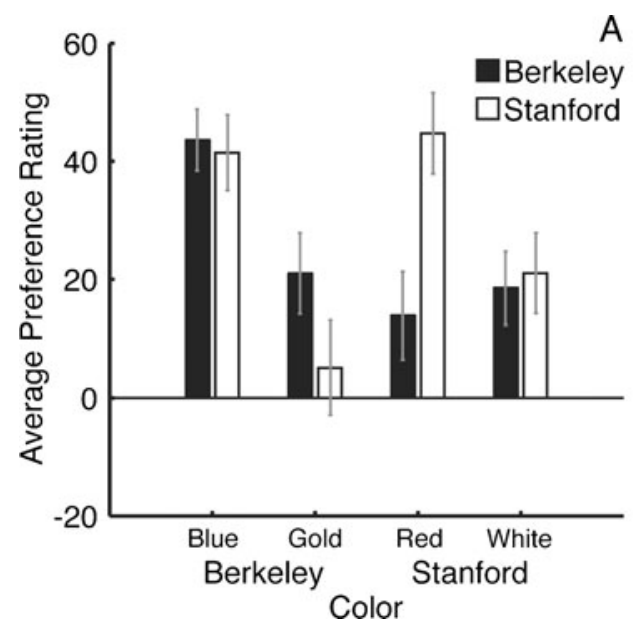

A

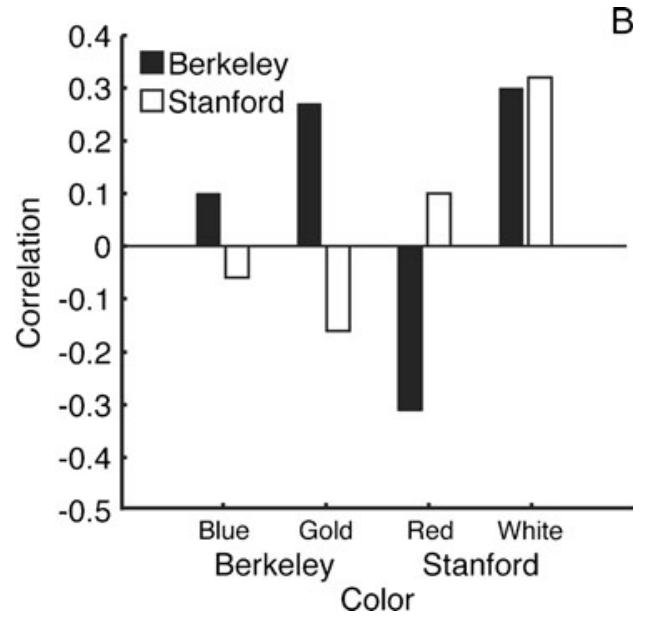

\section{Experiment 2}

Preference for color pairs

Although university colors can be encountered singly, they are more frequently seen in pairs. University seals, logos, and apparel, in addition to athletic uniforms, almost always contain both the school's primary and secondary colors. Moreover, there are typical proportions in which the two colors are combined: Berkeley blue with Berkeley gold accents and Stanford red with Stanford white accents. In Experiment 2, we compared Berkeley and Stanford students' preferences for color pairs in a figure-ground configuration (a small square centered on a large square), which included gold on blue (the primary Berkeley pair), blue on gold (the secondary Berkeley pair), white on red (the primary Stanford pair), and red on white (the secondary Stanford pair).

The EVT implies that associative sociocultural preference effects - both liking the color pairs of one's own university and disliking those of a rival university - will be stronger for pairs than for single university colors. The rationale is simply that, because color pairs are conjunctions of two colors, they tend to be associated with far fewer objects than are either of their component colors, and therefore are more likely to show associative preference effects arising from positive/negative affiliations with universities. Thirty-eight other color pairs were also tested, so that participants would not realize that the experiment was focused on university color pairs, which constituted only $9.5 \%$ of the pairs tested.

\section{Method}

Participants Ratings were obtained from the same participants as in Experiment 1 in the same experimental session, but after the single-color preference ratings and before the school spirit ratings.
Design, displays, and procedure The displays consisted of all 42 pair-wise figure-ground permutations of the following colors: Berkeley blue, Berkeley gold, Stanford red, Stanford white, light blue, dark yellow, and light red (see Table 1). We included light blue, dark yellow, and light red as distractor colors of similar hue that were different enough in lightness and saturation that they would not be perceived as related to either Berkeley or Stanford. Color pairs were presented in a figure-ground arrangement consisting of a small square $(100 \times 100$ pixels $)$ centered on a larger square $(300 \times 300$ pixels), as in Schloss and Palmer (2011). The display was centered on the monitor, with the same response scale and gray background as in Experiment 1. In all other respects, the procedure was the same as in Experiment 1.

\section{Results and discussion}

We tested for global differences between Berkeley and Stanford students' pair preferences by calculating a composite difference score, analogous to that for single colors in Experiment 1: the mean of the two Berkeley color pairs minus the mean of the two Stanford color pairs. As was the case for single colors, there was a reliable difference between Berkeley $(+20.5)$ and Stanford $(-31.7)$ students on this measure $\left[F(1,101)=19.06, p<.001, \eta^{2}=.16\right]$. These composite values for pairs are more extreme than those for the component colors (Berkeley, +16.1; Stanford, -9.6), as predicted by the EVT $[F(1,101)=$ $5.21, p<.05, \eta^{2}=.05$ ]. Also as in the results of Experiment 1, Berkeley students showed a positive correlation $(r=+.32$, $p<.01)$ between their composite pair preference scores and school spirit, whereas Stanford students showed a correspondingly negative correlation $(r=-.38, p<.01)$. These correlations were again more extreme for color pairs than for single colors (Berkeley students, $r=+.26$; Stanford students, $r=-.29$ ), also as predicted by the EVT. 
Comparisons between Berkeley and Stanford students' preference ratings for each of the four university-specific color combinations (see Fig. 2a) all show differences in the predicted directions ( $p=.06$ by a sign test). Combining the data from both primary and secondary pairs, Berkeley students liked pairs containing Berkeley blue and Berkeley gold more than Stanford students did $[F(1,101)=17.81$, $\left.p<.001, \eta^{2}=.15\right]$, and Stanford students liked pairs containing Stanford red and Stanford white more than Berkeley students did $\left[F(1,101)=4.86, p<.05, \eta^{2}=.05\right]$. More specifically, Berkeley students preferred both the primary Berkeley pair (gold on blue) $[F(1,101)=10.88$, $\left.p<.001, \eta^{2}=0.10\right]$ and the secondary Berkeley pair (blue on gold) $\left[F(1,101)=15.86, p<.001, \eta^{2}=0.14\right]$ more than Stanford students did. Conversely, Stanford students preferred the primary Stanford pair (white on red) $[F(1,101)=$ $\left.5.89, p<.01, \eta^{2}=.06\right]$ and the secondary Stanford pair (red on white) $\left[F(1,101)=2.29, p=.07, \eta^{2}=.02\right]$ more than Berkeley students did, although the latter difference only approached significance. Red on white may have shown a smaller effect because it is the less typical arrangement of Stanford's colors and/or because it is simply a more frequently seen color combination, given the pervasiveness of white backgrounds.

Correlations between preference for each university color and Berkeley and Stanford students' school spirit are shown in Fig. 2b. Although not all correlations are significant, all eight are all in the predicted directions $(p<.01$ by a sign test). Among Berkeley students, preference for Stanford's primary pair decreased significantly with Berkeley spirit (white on red, $r=-.37, p<.01$ ), and preference for their secondary pair marginally decreased with Berkeley spirit (red on white, $r=-.19, p=.08$ ). Preference for both Berkeley pairs tended to increase with Berkeley spirit (gold on blue, $r=+.18, p=.09$; blue on gold, $r=+.09, p=.25$ ), but not significantly so. Among Stanford students, preference for Berkeley pairs decreased significantly with Stanford spirit, although more for Berkeley's primary pair (gold on blue, $r=-.48, p<.01$ ) than for its secondary pair (blue on gold, $r=-.31, p<$ $.05)$. Preference for Stanford's primary pair increased reliably with Stanford spirit (white on red, $r=+.32, p<.05$ ), but the correlation for their secondary pair was only slightly positive $(r=+.01, p=.47)$. Within each university, primary pairs showed larger correlations, probably because they are more strongly associated with the university.

\section{General discussion}

The goal of this study was to test several predictions of the EVT related to institutional effects and individual differences in color preferences due to the magnitude and polarity of students' affiliations with two rival universities (Berkeley and Stanford) that are strongly associated with specific colors. As described within framework of the EVT, preference for university colors should not only be determined by school affiliation and spirit; they are determined by the average affective valence of all objects/ institutions associate with those colors.

Although some of the EVT's individual predictions fell short of statistical significance, the overall pattern of results over the two experiments provides compelling support for the theory. The EVT correctly predicted the direction for 8 out of 8 cases concerning whether Berkeley or Stanford students would show greater preference for the four single colors (Experiment 1) and the four pairs of colors associated with these universities (Experiment 2) $(p<.01$ by a sign test). It also correctly predicted the sign of 15 of 16 correlations measuring the dependence of these color preferences on self-rated school spirit for single colors (Experiment 1) and color pairs (Experiment 2$)(p<.001$ by a sign test). In addition, the EVT correctly predicted larger effects for color pairs than for single colors, both for
Fig. 2 a Berkeley (black bars) and Stanford (white bars) students' preference ratings for Berkeley figure/ground color pairs (gold on blue, blue on gold) and Stanford color pairs (white on red, red on white). Error bars represent the standard errors of the means. b Berkeley and Stanford students' correlations between spirit scores and preference for Berkeley and Stanford color pairs
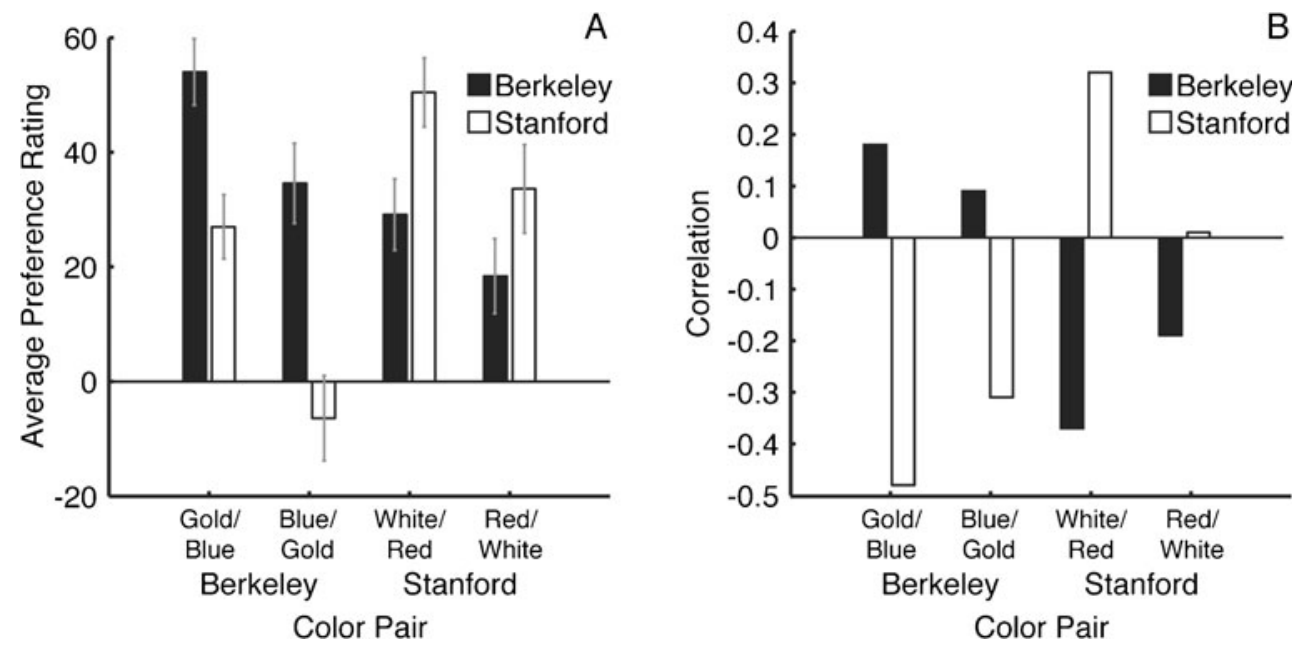

B 
composite preference effects and for spirit-preference correlations ( $p=.06$ by a sign test). Altogether, the EVT was supported in 27 of the 28 qualitative predictions $(p<.00001$ by a sign test). Moreover, the single prediction that went in the wrong direction - the correlation between school spirit and preference for white for Berkeley students being positive - has a plausible post-hoc explanation, given that some of Berkeley's sports uniforms are primarily white rather than just blue and gold.

The present findings speak to two important general issues concerning the EVT. One is the existence of learned versus inborn color preferences, and the second is whether color preferences might cause object preferences rather than object preferences causing color preferences. Palmer and Schloss (2010) framed the EVT in terms of the adaptive advantages of approach/avoidance behavior based, in part, on color preferences, if those preferences are correlated with what is beneficial/harmful to the organism for other reasons. Palmer and Schloss made this argument in terms that are more readily understood evolutionarily (e.g., being attracted to clear skies and clean water and repulsed by feces and rotting food), but they specifically allowed for learning that depends on feedback from the organism's life experiences with colored objects. The present effects of university affiliation and school spirit on color preferences must be learned rather than inborn, unless one believes that the colors of the university a person attends is genetically determined at birth.

The other important issue addressed by the present findings is whether people's preferences for color-associated objects and institutions actually cause their color preferences (the object-caused account of the EVT) or whether their color preferences cause their object preferences (an alternative, color-caused account). Palmer and Schloss (2010) reported evidence showing a very strong relation between people's affective responses to diagnostically colored objects and their preferences for those colors, but because the evidence was purely correlational, it did not specify the direction of causation. Clearly, color preferences can influence object preferences (e.g., choosing a T-shirt among otherwise identical ones), but the EVT implies that those color preferences arise primarily from previous experiences with objects that are characteristically those colors.

The present data are relevant to specifying the direction of causation, because the color-caused story required to account for them is so implausible. To be consistent with our findings that preferences for school colors differ systematically between Berkeley and Stanford students and vary systematically as a function of school spirit in the ways we have described, a color-caused account would require that (a) students chose their university because of how much they previously liked that university's colors; (b) the degree to which they previously liked the colors of their chosen university caused them to have the amount of school spirit they have; (c) they also chose their university because of how much they previously disliked the colors of its rival university; and (d) the degree to which they previously disliked the rival's colors caused them to have greater spirit for their own university. Each of these propositions is highly implausible on its own, and the conjunction of all four is downright absurd. The only reasonable explanation of the present findings, we submit, is that students' preferences for their university's colors (and against those of their university's rival) are caused, at least in part, by the degree to which they come to like/ dislike that university from their affective experiences with it, as predicted by the ecological valence theory.

Acknowledgments We thank Cathleen Moore and two anonymous reviewers for their helpful comments on the manuscript; Aryn Shellander, Mieke Leyssen, Sarah Linsen, Eli Strauss, Lily Lin, and Zoe Xu for assistance with data collection; Jay McClelland for the use of his lab space at Stanford University; and Jeremy Glick, Daniel Sternberg, and Rebecca Tortell for their help at Stanford. This research was supported by NSF Grant BCS-0745820 and by a Google Gift to S.E.P.

Open Access This article is distributed under the terms of the Creative Commons Attribution Noncommercial License which permits any noncommercial use, distribution, and reproduction in any medium, provided the original author(s) and source are credited.

\section{References}

Eysenck, H. J. (1941). A critical and experimental study of color preference. The American Journal of Psychology, 54, 385-391.

Granger, G. W. (1955). An experimental study of colour preferences. The Journal of General Psychology, 52, 3-20.

Guilford, J. P., \& Smith, P. C. (1959). A system of color preferences. The American Journal of Psychology, 72, 487-502.

Hurlbert, A. C., \& Ling, Y. (2007). Biological components of sex differences in colour preferences. Current Biology, 17, 623-625. doi:10.1016/j.cub.2007.06.022

McManus, I. C., Jones, A. L., Cottrell, J. (1981). "The aesthetics of colour," Perception, 10, 651-666

Palmer, S. E., \& Schloss, K. B. (2010). An ecological valence theory of human color preference. Proceedings of the National Academy of Sciences, 107, 8877-8882.

Schloss, K. B., \& Palmer, S. E. (2011). Aesthetic response to color combinations: Preference, harmony and similarity. Attention, Perception and Psychophysics. 73, 551-571.

Wyszecki, G., \& Stiles, W. S. (1967). Color science: Concepts and methods, quantitative data and formulas. New York: Wiley. 